\title{
Individual Genetic Variations Related to Satiety and Appetite Control Increase Risk of Obesity in Preschool-Age Children in the STRONG Kids Program
}

\author{
Yingying Wang ${ }^{a}$ Anthony Wang ${ }^{a}$ Sharon M. Donovan ${ }^{a, b}$ \\ Margarita Teran-Garciaa, b and the STRONG Kids Research Team \\ ${ }^{a}$ Division of Nutritional Sciences, and ${ }^{b}$ Department of Food Science and Human Nutrition, University of Illinois, \\ Urbana, III., USA
}

\section{Key Words}

Childhood obesity · Genetic scores · Breastfeeding · Genetic association studies

\begin{abstract}
Background/Aims: The burden of the childhood obesity epidemic is well recognized; nevertheless, the genetic markers and gene-environment interactions associated with the development of common obesity are still unknown. In this study, candidate genes associated to satiety and appetite control pathways with obesity-related traits were tested in Caucasian preschoolers from the STRONG Kids project. Methods: Eight genetic variants in genes related to obesity (BDNF, LEPR, FTO, PCSK1, POMC, TUB, LEP, and MC4R) were genotyped in 128 children from the STRONG Kids project (mean age 39.7 months). Data were analyzed for individual associations and to test for genetic predisposition scores (GPSs) with body mass index (BMI) and anthropometric traits (Z-scores, e.g. height-for-age Z-score, HAZ). Covariates included age, sex, and breastfeeding (BF) duration. Results: Obesity and overweight prevalence was 6.3 and $19.5 \%$, respectively, according to age- and sex-specific BMI percentiles. Individual genetic associations of MC4R and LEPR markers with HAZ were strengthened when BF duration was included as a covariate. Our GPSs show that, as the number of risk alleles increased, the risk of higher BMI and HAZ also in-
\end{abstract}

creased. Overall, the GPSs assembled were able to explain $2-3 \%$ of the variability in BMI and HAZ phenotypes. Conclusion: Genetic associations with common obesity-related phenotypes were found in the STRONG Kids project. GPSs assembled for specific candidate genes were associated with $\mathrm{BMI}$ and $\mathrm{HAZ}$ phenotypes.

(c) 2013 S. Karger AG, Base

\section{Introduction}

Obesity is a serious public health concern in the United States. Until recently, the obesity prevalence in children had been increasing steadily [1]. According to the Centers for Disease Control and Prevention (CDC), in $2007-2008,16.9 \%$ of children in the United States between 2 and 20 years of age were obese [ $\geq 95$ th percentile of body mass index (BMI) for age] and $31.7 \%$ of children were overweight ( $\geq 85-95$ th percentile of BMI for age). Approximately $80 \%$ of individuals who were obese during childhood and adolescence remain obese as adults [2].

The preschool age is a critical period for children to establish food intake patterns [3]. Increased food intake is an important factor leading to the onset of obesity. Regulation of food intake is a complex trait resulting from the interaction of physiological, psychological, and socio-environmental elements as well as an individual's genetic

\section{KARGER}

E-Mail karger@karger.com

www.karger.com/hhe
(C) 2013 S. Karger AG, Basel

0001-5652/13/0754-0152\$38.00/0
Margarita Teran-Garcia, MD, $\mathrm{PhD}$

University of Illinois at Urbana-Champaign

905 S Goodwin Avenue, 437 Bevier Hall

Urbana, IL 61801 (USA)

E-Mail teranmd@illinois.edu 
profile. In fact, several studies have indicated that there is an association between eating behaviors, food preferences, and selection of portion size with individual genetic variations [4-9].

The STRONG (Synergistic Theory and Research on Obesity and Nutrition Group) Kids program is a 3-year longitudinal cross-disciplinary study designed to identify risk factors for excessive weight gain and obesity development in preschool-age children. The STRONG Kids program was developed under an ecological framework with several spheres of influence that we termed the 6Cs model: cell, child, clan, community, country, and culture [10]. The effects of these environmental factors and their interactions on the onset of childhood obesity and the sphere of biological influence ('the Cell'), which encompasses the genetic and metabolic individuality that affects the risk of diseases associated with childhood obesity, were studied [11].

Despite considerable technological advances using hypothesis-free [genome-wide association studies (GWAS)] approaches to understand the genetics of obesity development, the underlying physiopathological mechanisms are not well understood. Not all genetic markers identified through GWAS from adult BMI have been replicated in common childhood obesity, and some loci identified have been only found when extreme forms of childhood obesity and large cohorts in meta-analyses were investigated (e.g. BDNF, FTO, LEPR, MC4R, and POMC) [1214]. Furthermore, the proportion of variability explained by GWAS candidate loci is modest (less than 10\%) [15]. Breastfeeding (BF) could be an important environmental factor - 'the exposome' - that could explain the 'missing heritability' in meta-analyses of GWAS for obesity. There are limited data on the influence of BF in the strength or direction of genetic associations (e.g. [16]). New data suggest that the relative contribution of each locus to obesity differs whether common or severe forms of obesity are investigated, as there is incomplete overlap between influential risk loci of severe versus common obesity [12]. Importantly, many studies only use child BMI percentiles or BMI Z-scores as a proxy for obesity phenotypes, and other potentially useful anthropometric measurements are overlooked in GWAS for childhood obesity. In particular, height-for-age Z-scores (HAZ) could provide important information to better understand the impact of growth on the development of common childhood obesity. Recently, the assembly of genetic predisposition scores (GPSs) has been shown to be a useful tool in evaluating the risk for chronic diseases, including obesity [13, 17-19]. GPSs could be assembled by replication of GWAS and marker hypothesis-driven selection.

Candidate Genes Associated with Satiety

and Appetite in Preschool Children
Individual variations in genes involved or potentially related to the leptin-melanocortin signaling pathway have been associated with symptoms of poor appetite control and obesity-related phenotypes [7, 20-22]. There is a need to replicate findings from GWAS using a systems biology approach with markers located in or nearby genes involved in regulatory hypothalamic pathways (BDNF, FTO, LEPR, MC4R, and POMC) and to evaluate if other genetic associations identified in this network (LEP, PCSK1, and TUB) could strengthen our understanding of obesity risk in preschoolers [23]. LEP and PCSK1 are among the susceptibility genes responsible for nonsyndromic childhood obesity and participate in the integration of peripheral and neuronal signals through the leptin-melanocortin hypothalamic pathway and are also responsible for maintaining energy balance through food consumption and energy expenditure [22]. The TUB gene encodes a transcription factor member of the $G$ protein-coupled receptors (GPCRs) that regulates gene expression after translocation from its membrane-bound location into the nucleus [24]. TUB has been identified as a candidate gene for late-onset obesity development [2528 ] and has been recently implicated in waist circumference regain after weight loss and the interindividual responses to dietary interventions [25]. However, the results of genetic association studies for the TUB gene are not consistent, and there are no data on the impact of TUB markers on obesity-related phenotypes in preschoolers. Recently, enrichment of copy number variants in a network of 13 genes encoding GPCRs has been identified by GWAS as candidates for severe early-onset obesity [12].

The purpose of this study was to investigate genetic associations and common obesity-related phenotypes in preschool-age children participating in the STRONG Kids program. By constructing GPSs, we tested for individual and cumulative effects of risk alleles. We hypothesized that the GPS approach provides a better indicator of the polygenic nature of common obesity, especially when markers are selected from both GWAS and genes involved in the hypothalamic signaling pathway.

\section{Subjects and Methods}

Sample Collection

Our sample population consisted of Caucasian children $(\mathrm{n}=$ 128) from the STRONG Kids program. Height and weight were collected by trained personnel at day care centers in the Champaign-Urbana, Illinois area by using a portable stadiometer (SECA, Hanover, Md., USA) and an electronic remote display scale 
(Health-o-Meter, Jarden Consumer Solutions, Boca Raton, Fla., USA). The precision level was set to $0.1 \mathrm{~cm}$ for height and $0.1 \mathrm{~kg}$ for weight measurements. Saliva samples were collected using the Saliva Collection Kit for Young Children (DNA Genotek Inc., Kanata, Ont., Canada) to extract the genomic DNA for genotyping.

\section{Anthropometric Measurements}

From height and weight data, BMI, BMI percentile, and anthropometric Z-scores, including weight-for-age (WAZ), HAZ, weight-for-height (WHZ), and BMI-for-age Z-scores (BMIZ) were calculated using the standard SAS Program from CDC (http://www.cdc.gov/nccdphp/dnpao/growthcharts/resources/ sas.htm). Z-scores express the standard deviation from the mean to indicate a child's weight and height status according to the sexand age-specific CDC growth charts from 2000.

\section{DNA Extraction}

Genomic DNA was extracted from saliva samples according to the protocol adopted from the manual for the purification of DNA from $4.0 \mathrm{ml}$ Oragene DNA/saliva. The average DNA yield per sample was $4.17 \mu \mathrm{g}$, with an average of $260 / 280$ OD ratio of $1.80 \pm 0.21$ measured by NanoDrop (Thermo Scientific, Wilmington, Del., USA).

\section{Genotyping}

Selected single nucleotide polymorphisms (SNPs) were genotyped by fluorescent polarization or using the TaqMan assay system.

\section{Fluorescent Polarization}

Template-directed dye-terminator incorporation with fluorescence polarization detection was used for genotyping SNPs rs925946, rs1137101, rs8057044, rs6235, rs2272382, and rs7799039 in or near the genes of BDNF, LEPR, FTO, PCSK1, TUB, and LEP, respectively. PCR reaction was performed with $5 \mathrm{ng}$ dry genomic DNA, followed by the single base pair extension procedure according to the protocol developed by Kwok [29]. Fluorescent signals were measured by the VICTOR Multi-label Plate Reader (Perkin Elmer Life Sciences, Waltham, Mass., USA). Genotypes were identified by built-in software and independently verified by two researchers without discordance. To check the accuracy of genotyping and genotype assignment for each SNP, at least $10 \%$ of the samples were randomly repeated, including both positive and negative controls. The concordance for the replicates was $100 \%$.

TaqMan Assay

The MC4R-rs17782313 SNP was genotyped by predesigned allelic discrimination TaqMan assays (Applied Biosystems, Foster City, Calif., USA) and the GeneAmp 7900 Real-Time PCR System (Applied Biosystems). PCR was performed in a 384-well format with a 5 - $\mu$ l reaction volume and $5 \mathrm{ng}$ dry genomic DNA, subjected to $95^{\circ} \mathrm{C}$ for $15 \mathrm{~min}$, and $40 \mathrm{cycles}$ of $92^{\circ} \mathrm{C}$ for $15 \mathrm{~s}$ and $60^{\circ} \mathrm{C}$ for $1 \mathrm{~min}$. The fluorescent intensity of the dyes in each well was measured and recorded into an ABI system. Genotypes were assigned using Sequence Detection Software 2.4 (Applied Biosystems). The success rate was $95 \%$.

Statistical Analyses

Allele frequencies were estimated by the gene counting method, and $\chi^{2}$ tests were used to identify significant departures from
Table 1. Descriptive characteristics of the STRONG Kids Caucasian cohort $(\mathrm{n}=128)$

\begin{tabular}{lcc}
\hline Variable & Mean & $95 \%$ CI \\
\hline Age, months & 39.9 & 38.6 to 41.1 \\
Weight, kg & 15.6 & 15.2 to 15.9 \\
Height, cm & 97.1 & 96.1 to 98.1 \\
BMI & 16.5 & 16.3 to 16.7 \\
BMIPCT & 65.3 & 61.1 to 69.5 \\
WAZ & 0.4 & 0.2 to 0.5 \\
HAZ & 0.1 & -0.1 to 0.3 \\
WHZ & 0.5 & 0.3 to 0.6 \\
BMIZ & 0.5 & 0.4 to 0.6
\end{tabular}

BMIPCT = Percentile for BMI-for-age, according to the sexspecific 2000 CDC growth charts.

Hardy-Weinberg equilibrium. The selected SNPs were tested for additive genotype effect on BMI percentile, WAZ, HAZ, and BMIZ values in general linear models using SAS 9.2 (SAS Institute Inc., Cary, N.C., USA). The parents of the children from the STRONG Kids program completed a comprehensive survey including weaning- and nutrition-related aspects under our ecological approach (6Cs model) to understand obesity development [10]. The effect of $\mathrm{BF}$ duration in the genetic associations was tested as a categorical covariate under two different approaches. First, as three categories of BF duration: (1) never been BF; (2) BF less than 6 months, and (3) BF for 6 months or more. Second, as a binary variable: (1) 'never BF' or (2) 'ever BF', representing the combination of BF categories (2) and (3) from the first approach. The general linear models were used to examine the association of the 8 SNPs investigated with BMI percentiles and CDC Z-scores, assuming an additive effect, without adjustment for BF duration. Genotype-phenotype associations were tested using the publicly available Plink software (http://pngu.mgh.harvard.edu/ purcell/plink/index.shtml). GPSs were calculated and tested for association with the obesityrelated phenotypes according to an additive risk allele model. Bootstrapping was used to estimate bias and confidence intervals and to reevaluate associations observed (online suppl. material, www.karger.com/doi/10.1159/000353880).

\section{Results}

Descriptive data of the 128 Caucasian preschoolers participating in this STRONG Kids cohort are presented in table 1 , including mean and $95 \%$ confidence intervals for age, weight, height, BMI, and Z-scores. No significant differences in age, height, BMI, or Z-scores were detected between boys and girls or in groups with different $\mathrm{BF}$ duration. Ninety-seven (75.8\%) of the participating children were classified as 'ever BF', which is similar to the national 'ever BF' rate of $74 \%$ [30]. 
Table 2. Selected SNPs and associations with HAZ, WAZ, and BMIZ phenotypes

\begin{tabular}{|c|c|c|c|c|c|c|c|c|c|c|c|}
\hline \multirow{2}{*}{$\begin{array}{l}\text { Genetic } \\
\text { marker } \\
\text { (SNP) }\end{array}$} & \multirow[t]{2}{*}{ Gene } & \multicolumn{2}{|c|}{ Basic information } & \multicolumn{2}{|c|}{ SKP cohort $(n=128)$} & \multicolumn{2}{|c|}{$\begin{array}{l}\text { HAZ association } \\
\text { model, } \mathrm{p} \text { value }\end{array}$} & \multicolumn{2}{|c|}{$\begin{array}{l}\text { WAZ association } \\
\text { model, } p \text { value }\end{array}$} & \multicolumn{2}{|c|}{$\begin{array}{l}\text { BMIZ association } \\
\text { model, p value }\end{array}$} \\
\hline & & location & reported MAF & detected MAF & HW p value & model 1 & model 2 & model 1 & model 2 & model 1 & model 2 \\
\hline rs925946 & $B D N F$ & Chr11 & Т 0.355 & Т 0.222 & 0.85 & 0.3973 & 0.1508 & 0.8885 & 0.7194 & 0.2776 & 0.4735 \\
\hline rs8057044 & FTO & Chr16 & G 0.461 & A 0.483 & 0.51 & 0.7378 & 0.8398 & 0.5297 & 0.5076 & 0.4651 & 0.4172 \\
\hline rs7799039 & $L E P$ & Chr7 & A 0.317 & A 0.400 & 0.29 & 0.0696 & 0.0141 & 0.5019 & 0.3232 & 0.7675 & 0.6885 \\
\hline rs1137101 & $L E P R$ & Chr1 & A 0.482 & G 0.475 & 0.83 & 0.9080 & 0.7981 & 0.7879 & 0.9191 & 0.5540 & 0.5679 \\
\hline rs17782313 & $M C 4 R$ & Chr18 & C 0.259 & C 0.266 & 0.87 & 0.0376 & 0.0213 & 0.1799 & 0.1060 & 0.5854 & 0.6486 \\
\hline rs6235 & PCSK1 & Chr5 & C 0.278 & C 0.294 & 0.18 & 0.3094 & 0.1417 & 0.1329 & 0.0490 & 0.0967 & 0.0874 \\
\hline rs934778 & POMC & Chr2 & C 0.384 & C 0.319 & 0.97 & 0.7679 & 0.2084 & 0.5517 & 0.0103 & 0.4641 & 0.1848 \\
\hline rs 2272382 & TUB & Chr11 & A 0.378 & A 0.313 & 0.90 & 0.4831 & 0.1295 & 0.4439 & 0.3521 & 0.5387 & 0.5004 \\
\hline
\end{tabular}

$\mathrm{HW}=$ Hardy-Weinberg equilibrium.

Model 1: genetic association using a general linear model. Model 2: includes BF duration as a covariate (3 categories: never BF, BF for less than 6 months, and BF for 6 or more months).

The minor allele frequencies (MAF) of this cohort are shown in table 2. The MAF of all genotyped markers were consistent with those reported in Caucasian populations (as reported for CEU in HapMap 37.1). Although there were minor differences for MAF in LEPR-rs1137101 and FTO-rs8057044 markers in our cohort, the discrepancy was not significant for both SNPs, as MAF were close to 0.5 . We did not detect any significant deviation from Hardy-Weinberg equilibrium for any of the SNPs investigated (table 2).

The associations of individual SNPs with HAZ, WAZ, and BMIZ are summarized in table 2. The MC4Rrs17782313 SNP was significantly associated with HAZ $(\mathrm{p}=0.037)$. The association remained significant when $\mathrm{BF}$ duration was included as a covariate $(\mathrm{p}=0.021)$. The minor allele (A) of LEP-rs7799039 was associated with an increase in $\mathrm{HAZ}$ at $0.26 \mathrm{Z}$-score units per allele only when $\mathrm{BF}$ was incorporated as a covariate. Although there were no significant associations in the TUB-rs2272382 SNP for any of the phenotypes investigated, we found an interaction effect between $\mathrm{BF}$ and the association with HAZ $(\mathrm{p}=0.0021$, data not shown). No other genetic associations with the HAZ phenotype were found, with or without inclusion of BF duration as a covariate. The PSCK1rs6235 SNP was associated with WAZ only after inclusion of $\mathrm{BF}$ as a covariate. No other associations were found for other phenotypes investigated including WAZ and BMI percentile.

The GPSs for BMI percentile, WAZ, HAZ, and BMIZ were normally distributed. BMIZ and BMI percentile GPSs were very similar. In general, as the number of risk

Candidate Genes Associated with Satiety

and Appetite in Preschool Children alleles increased, the risk of having higher BMI percentile, HAZ, and WAZ increased. Children with 12 risk alleles had an average of 1.2 WAZ units more than children with only 3 risk alleles. The percentage of the variability explained by GPSs was less than $2 \%$ for all phenotypes tested. Only when using a bootstrapping modeling with 100, 500 , and 1,000 replicates we were able to explain 2-9\% of the variability with the genotypes (data not shown). The selected markers in the POMC, FTO, MC4R, and LEPR genes were commonly included as major contributors in the initial steps of the stepwise regression models. Figure 1 displays the BMI percentile, HAZ, and WAZ distribution of alleles as well as the increases in risk for these obesity-related phenotypes.

\section{Discussion}

The objective of this study was to determine whether individual genetic variation of genes with well-defined roles in regulating the hypothalamic signaling pathway would be associated with early-onset obesity-related traits in preschoolers. We observed several individual associations between selected genetic markers (TUB, MC4R, LEP, and PCSK1) and obesity-related phenotypes. Additionally, we took a novel approach in investigating the cumulative effect of risk alleles in the hypothalamic pathway on obesity-related traits including BMI percentile, WAZ, and HAZ with modest findings, and evaluated the impact of $\mathrm{BF}$ as a covariate. Our results suggest that the impact of some environmental variables (e.g. 

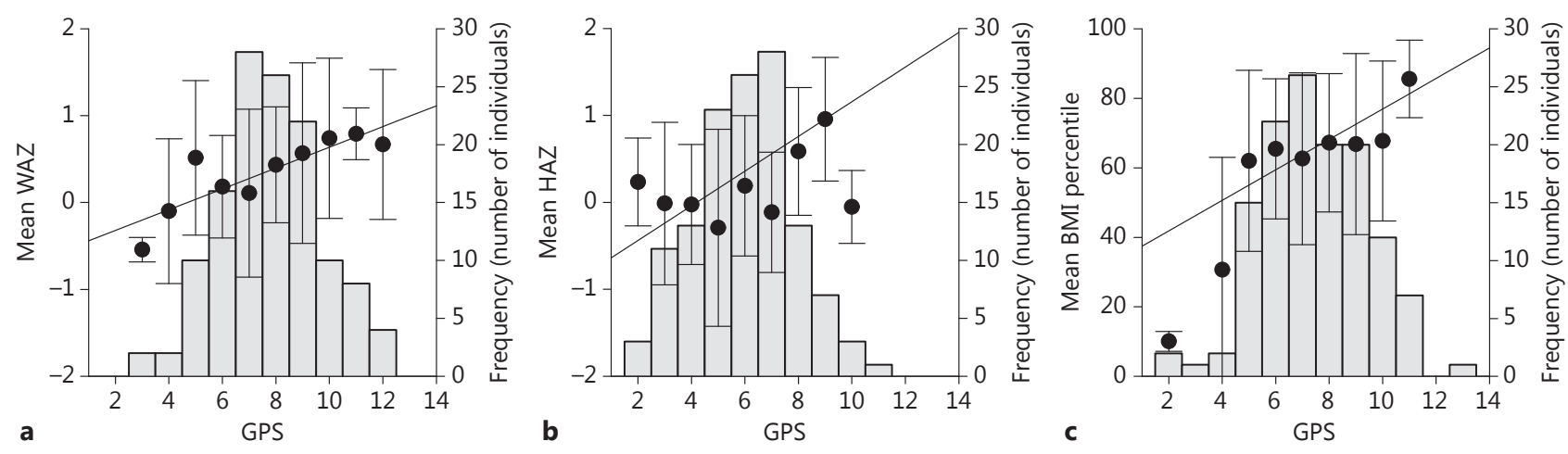

Fig. 1. Distribution of GPSs and cumulative effects of risk alleles for the 3 obesity-related phenotypes (WAZ, HAZ, and BMI percentiles) in the STRONG Kids cohort. Data presented show means \pm SD for WAZ (a), HAZ (b), and BMI percentiles (c) according to the growth curves from CDC 2000. The x-axes indicate GPSs (number of risk alleles) for the 8 SNPs genotyped in participating preschoolers $(n=128)$. The left $y$-axes indicate the obesity-related phenotype, and the right $y$-axes indicate the distribution and frequency of the observed risk alleles (gray bars). Lines across each graphic represent a simple regression of the mean for the 3 obesityrelated phenotypes per risk allele, and error bars represent SD.
$\mathrm{BF}$ ) warrants further evaluation. Whether $\mathrm{BF}$ is a protective factor for obesity development is still a matter of debate [31]. Further cohorts and genetic studies may provide new insights into the impact of this important element on 'the exposome' that could explain the 'missing heritability' in meta-analyses of GWAS for childhood obesity.

Individual genetic associations for common childhood obesity have been revised recently, and even when some of the candidate genes selected have been identified by GWAS for adult obesity-related phenotypes, the markers (SNPs) investigated here were selected at the time when no replication or GWAS for young children (less than 5 years old) was available. In fact, one selected marker (TUB) still has limited information and replication, even though it has been associated with eating behavior and preference for carbohydrate intake [28]. The TUB gene encodes a bipartite transcription factor related to GPCRs that regulates gene expression after translocation from its membrane-bound location into the nucleus [24]. To date, results from genetic association studies on obesity and the TUB gene are inconsistent. To our knowledge, this is the first study to show the impact of this TUB SNP on obesityrelated phenotypes in preschool-age children.

Except for the SNP in the BDNF gene, which was directly associated with BMI percentile, the other SNPs in the TUB, MC4R, and LEP genes had stronger associations with HAZ in the STRONG Kids cohort. Our observations concur with previous reports showing that taller children are more likely to become overweight or obese compared to their normal-height counterparts [32]. The MC4R gene encodes a downstream receptor in the leptin signaling pathway contributing to the central melanocortinergic system, which plays a vital role in metabolic regulation and energy intake [33]. The MC4R gene was one of the first and most widely studied loci from which genetic variations were associated with human obesity, and recent reports have shown associations between the rs17782313 SNP and obesity in GWAS as well as type 2 diabetes in a meta-analysis $[34,35]$. Contrary to the findings in our study, the MC4R-rs17782313 variant was not associated with HAZ after adjusting for age, gender, and BMIZ in children of a Chilean family cohort. This study did, however, link MC4R with children's satiety and enjoyment of food [36]. The STRONG Kids program database contains extensive phenotypic data, and forthcoming analyses will examine the relationship between satiety and appetite control as measured by the Children's Eating Behavior Questionnaire (CEBQ) and individual variation in other genes, including MC4R.

Our study has several limitations and strengths. First, we only genotyped a few SNPs in a pathway of hypothalamic satiety signals summarized in figure 2 , and not all selected markers have shown either a functional effect or a direct causal effect. Furthermore, it is well known that many other metabolic pathways influence fat storage, en- 
Fig. 2. Schematic representation highlighting the key genes in the leptin-melanocortin pathway involved in signaling satiety. In response to increasing fat storage, the adipose tissue releases leptin, which binds to the leptin receptor in the arcuate nucleus (ARC) of the hypothalamus having an anorexigenic effect. Leptin acts concurrently through its receptor to inhibit the orexigenic factors AgRP and NPY. This promotes the expression of proopiomelanocortin (POMC), a precursor of several biologically active polypeptides and which is cleaved by PCSK1 forming alpha-melanocyte stimulating hormone ( $\alpha-M S H)$, which acts on MC4R, a receptor in the paraventricular nucleus (PVN). Through unknown mechanisms, MC4R activation leads to appetite suppression through brain-derived neurotrophic factor (BDNF) and tropomyosin-related kinase $B(\operatorname{Trk} B)$ in the ventromedial nucleus $(\mathrm{VMN}) . \mathrm{BBB}=$ Blood-brain barrier.

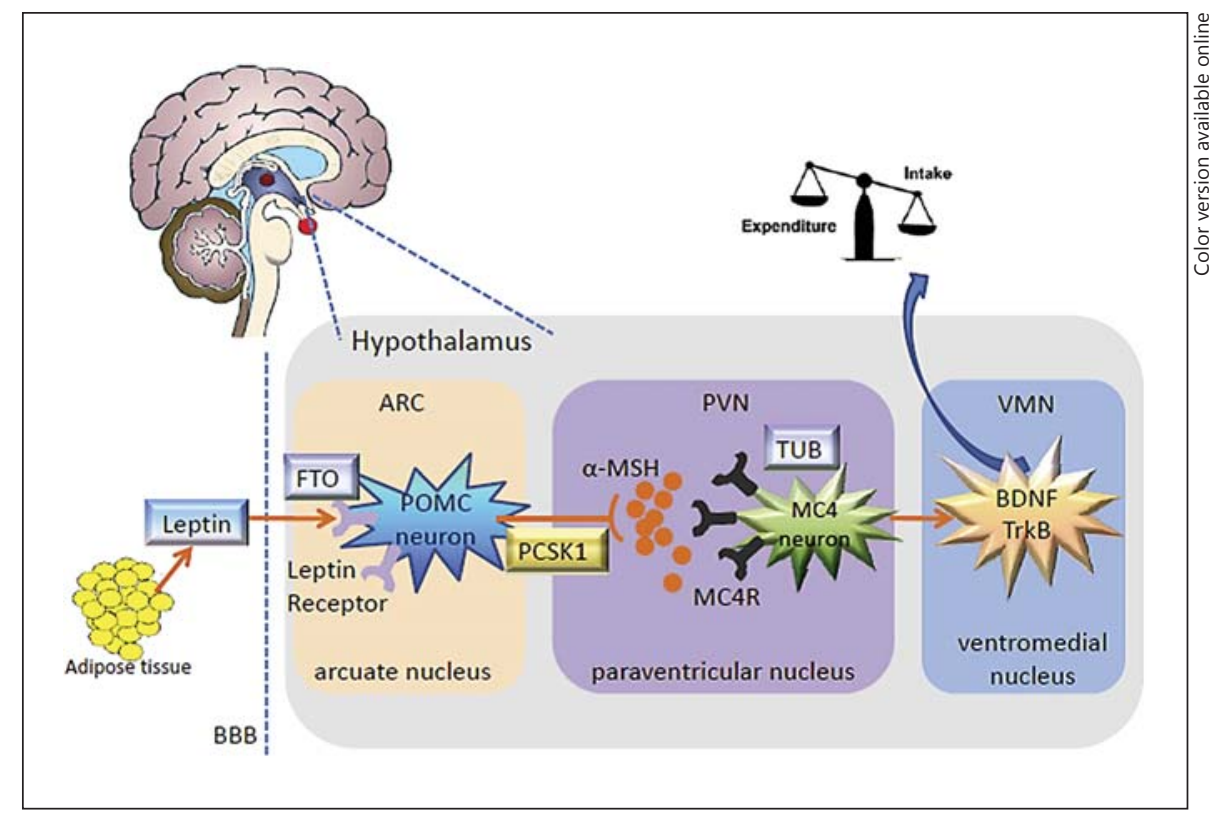

ergy homeostasis, and obesity development. We recognize that highlighting a pathway-based approach for association is primarily theoretical; this report represents only a selective application of a pathway approach for common childhood obesity. Second, the small sample size likely precludes us from detecting other associations that have been previously reported. As our sample size is limited, the absence of significance in the relationships analyzed does not necessarily indicate a lack of association. Replications with larger and more diverse cohorts are still needed. Despite limitations in our sample size for association studies, our work supports previous findings in small cohorts investigating individual genetic variations and their relationships with obesity. In addition, our findings confirm that associations reported previously in Caucasian populations by both GWAS and meta-analyses $[14,19]$ are present in children as young as $3-5$ years old. The strengths of this study relate to the age group selected for investigation and the overall aims of the STRONG Kids project wherein extensive data on child phenotype and environmental factors are being collected in order to understand the spheres of influence in childhood obesity development. There are few studies that have investigated the determinants of childhood obesity during critical periods of growth while simultaneously collecting extensive phenotypic data in an ecological context (the 6Cs model) [10]. Herein, only the impact of BF duration and the interaction effect on the genetic association were tested. It is expected that future analyses and the

Candidate Genes Associated with Satiety and Appetite in Preschool Children longitudinal data that are being collected will allow us to investigate additional genetic and environmental components and their interactions more comprehensively.

In conclusion, common genetic variants for obesityrelated phenotypes have small but cumulative effects on obesity risk for preschool-age children. Previous genetic epidemiological reports have evidenced the importance of genes involved in or related to the leptin-melanocortin pathway in the regulation of satiety and risk of developing obesity [37]. However, one difficult question remains: To what extent do these genes and alleles work to regulate molecular pathways? Despite considerable technological advances using hypothesis-free (GWAS) approaches to understand obesity development, the underlying physiopathological mechanisms are not well understood. For some loci that have been identified as being associated with obesity or obesity-related phenotypes, the functional role of these genetic variations remains to be elucidated. Many of the current studies, particularly some GWAS, have highlighted the importance of multi-locus effects on the genetic contribution to the onset of obesity $[38,39]$. It is still premature to know whether individualized pharmacological treatment based on genetic information will be used in clinical practice and whether it will have a large impact in the control of energy balance. However, it will be useful for parents to become aware of the risk of certain behaviors and help their children to practice healthful eating habits before the child's genetic predisposition is triggered by the current obesogenic environment. 


\section{Acknowledgements}

This paper was written on behalf of the STRONG Kids Research Team: Kelly Bost, Sharon Donovan, Barbara Fiese, Diana Grigsby-Toussaint, Kristen Harrison, Janet Liechty, Brent McBride, Margarita Teran-Garcia, and Angela Wiley. We would also especially like to thank all children, their parents, and all coordina- tion personnel for overseeing data collection by our undergraduate and graduate research teams. Support for this study was provided by the Illinois Council for Food and Agriculture Research (CFAR). This project was supported by the USDA National Institute of Food and Agriculture, Hatch Project No. 600109-698000-698354 and the University of Illinois Research Board Grant No. 10278 (to M.T.-G.).

\section{References}

$\checkmark 1$ Ogden CL, Carroll MD, Curtin LR, Lamb MM, Flegal KM: Prevalence of high body mass index in US children and adolescents, 2007-2008. JAMA 2010;303:242-249.

-2 Whitaker RC, Wright JA, Pepe MS, Seidel KD, Dietz WH: Predicting obesity in young adulthood from childhood and parental obesity. N Engl J Med 1997;337:869-873.

3 Birch LL: Development of food acceptance patterns in the first years of life. Proc Nutr Soc 1998;57:617-624.

4 Clement K, Vaisse C, Lahlou N, Cabrol S, Pelloux V, Cassuto D, Gourmelen M, Dina C, Chambaz J, Lacorte JM, Basdevant A, Bougneres P, Lebouc Y, Froguel P, Guy-Grand B: A mutation in the human leptin receptor gene causes obesity and pituitary dysfunction. $\mathrm{Na}-$ ture 1998;392:398-401.

$\checkmark 5$ Cecil JE, Tavendale R, Watt P, Hetherington MM, Palmer CN: An obesity-associated FTO gene variant and increased energy intake in children. N Engl J Med 2008;359:2558-2566.

-6 Morton GJ, Cummings DE, Baskin DG, Barsh GS, Schwartz MW: Central nervous system control of food intake and body weight. Nature 2006;443:289-295.

7 Krude H, Biebermann H, Luck W, Horn R, Brabant G, Gruters A: Severe early-onset obesity, adrenal insufficiency and red hair pigmentation caused by POMC mutations in humans. Nat Genet 1998;19:155-157.

-8 Farooqi IS, Wangensteen T, Collins S, Kimber W, Matarese G, Keogh JM, Lank E, Bottomley B, Lopez-Fernandez J, Ferraz-Amaro I, Dattani MT, Ercan O, Myhre AG, Retterstol L, Stanhope R, Edge JA, McKenzie S, Lessan N, Ghodsi M, De Rosa V, Perna F, Fontana S, Barroso I, Undlien DE, O’Rahilly S: Clinical and molecular genetic spectrum of congenital deficiency of the leptin receptor. N Engl J Med 2007;356:237-247.

-9 Spiegelman BM, Flier JS: Obesity and the regulation of energy balance. Cell 2001;104:531543.

10 Harrison K, Bost KK, McBride BA, Donovan SM, Grigsby-Toussaint DS, Kim J, Liechty JM, Wiley AR, Teran-Garcia M, Jacobsohn GC: Toward a developmental conceptualization of contributors to overweight and obesity in childhood: the $6 \mathrm{Cs}$ model. Child Devel Perspect 2011;5:50-58.

11 Teran-Garcia M, Rankinen T, Bouchard C: Genes, exercise, growth, and the sedentary, obese child. J Appl Physiol 2008;105:9881001.

12 Wheeler E, Huang N, Bochukova EG, Keogh JM, Lindsay S, Garg S, Henning E, Blackburn H, Loos RJ, Wareham NJ, O'Rahilly S, Hurles ME, Barroso I, Farooqi IS: Genome-wide SNP and $\mathrm{CNV}$ analysis identifies common and low-frequency variants associated with severe early-onset obesity. Nat Genet 2013;45:513517.

13 Mitchell JA, Hakonarson H, Rebbeck TR, Grant SF: Obesity-susceptibility loci and the tails of the pediatric BMI distribution. Obesity (Silver Spring) 2013, E-pub ahead of print.

14 Bradfield J, Taal HR, Timpson NJ, et al: A genome-wide association meta-analysis identifies new childhood obesity loci. Nat Genet 2012;44:526-531.

15 Ramachandrappa S, Farooqi IS: Genetic approaches to understanding human obesity. J Clin Invest 2011;121:2080-2086.

16 Dedoussis GV, Yannakoulia M, Timpson NJ, Manios Y, Kanoni S, Scott RA, Papoutsakis C, Deloukas P, Pitsiladis YP, Davey-Smith G, Hirschhorn JN, Lyon HN: Does a short breastfeeding period protect from FTO-induced adiposity in children? Int J Pediatr Obes 2011;6:e326-e335.

17 Anderson JL, Horne BD, Camp NJ, Muhlestein JB, Hopkins PN, Cannon-Albright LA, Mower CP, Park JJ, Clarke JL, Nicholas ZP, McKinney JT, Carlquist JF: Joint effects of common genetic variants from multiple genes and pathways on the risk of premature coronary artery disease. Am Heart J 2010;160: 250-256.e33.

18 Chung WK, Patki A, Matsuoka N, Boyer BB, Liu N, Musani SK, Goropashnaya AV, Tan PL, Katsanis N, Johnson SB, Gregersen PK, Allison DB, Leibel RL, Tiwari HK: Analysis of 30 genes ( 355 SNPs) related to energy homeostasis for association with adiposity in European-American and Yup'ik Eskimo populations. Hum Hered 2009;67:193-205.

$>19$ Elks CE, Loos RJ, Sharp SJ, Langenberg C, Ring SM, Timpson NJ, Ness AR, Davey Smith G, Dunger DB, Wareham NJ, Ong KK: Genetic markers of adult obesity risk are associated with greater early infancy weight gain and growth. PLoS Med 2010;7:e1000284.

20 den Hoed M, Westerterp-Plantenga MS, Bouwman FG, Mariman EC, Westerterp KR:
Postprandial responses in hunger and satiety are associated with the rs 9939609 single nucleotide polymorphism in FTO. Am J Clin Nutr 2009;90:1426-1432.

21 Montague CT, Faroogi IS, Whitehead IP, Soos MA, Rau H, Wareham NJ, Sewter CP, Digby JE, Mohammed SN, Hurst JA, Cheetham CH, Earley AR, Barnett AH, Prins JB, O'Rahilly S: Congenital leptin deficiency is associated with severe early-onset obesity in humans. Nature 1997;387:903-908.

22 Williams G, Harrold JA, Cutler DJ: The hypothalamus and the regulation of energy homeostasis: lifting the lid on a black box. Proc Nutr Soc 2000;59:385-396.

23 Garver W, Newman S, Gonzales-Pacheco D, Castillo J, Jelinek D, Heidenreich R, Orlando $\mathrm{R}$ : The genetics of childhood obesity and interaction with dietary macronutrients. Genes Nutr 2013;8:271-287.

24 Santagata S, Boggon TJ, Baird CL, Gomez CA, Zhao J, Shan WS, Myszka DG, Shapiro L: Gprotein signaling through tubby proteins. Science 2001;292:2041-2050.

25 Larsen LH, Angquist L, Vimaleswaran KS Hager J, Viguerie N, Loos RJ, Handjieva-Darlenska T, Jebb SA, Kunesova M, Larsen TM, Martinez JA, Papadaki A, Pfeiffer AF, van Baak MA, Sorensen T, Holst C, Langin D, Astrup A, Saris WH: Analyses of single nucleotide polymorphisms in selected nutrient-sensitive genes in weight-regain prevention: the DIOGENES study. Am J Clin Nutr 2012;95: 1254-1260.

26 Shiri-Sverdlov R, Custers A, van Vliet-Ostaptchouk JV, van Gorp PJ, Lindsey PJ, van Tilburg $\mathrm{JH}$, Zhernakova S, Feskens EJ, van der $\mathrm{AD}$, Dolle ME, van Haeften TW, Koeleman BP, Hofker $\mathrm{MH}$, Wijmenga $\mathrm{C}$ : Identification of TUB as a novel candidate gene influencing body weight in humans. Diabetes 2006;55:385-389.

27 Snieder H, Wang X, Shiri-Sverdlov R, van Vliet-Ostaptchouk JV, Hofker MH, Perks U, Spector TD, O'Dell SD: TUB is a candidate gene for late-onset obesity in women. Diabetologia 2008;51:54-61.

28 van Vliet-Ostaptchouk JV, Onland-Moret NC, Shiri-Sverdlov R, van Gorp PJ, Custers A, Peeters $\mathrm{PH}$, Wijmenga C, Hofker $\mathrm{MH}$, van der Schouw YT: Polymorphisms of the TUB gene are associated with body composition and eating behavior in middle-aged women. PLoS One 2008;3:e1405. 
29 Kwok PY: High-throughput genotyping with primer extension fluorescent polarization detection. Curr Protoc Hum Genet 2004; Chapter 2:Unit 2.11

30 Lowe NK: The Surgeon General's call to action to support breastfeeding. J Obstet Gynecol Neonatal Nurs 2011;40:387-389.

31 Casazza K, Pate R, Allison DB: Myths, presumptions, and facts about obesity. N Engl J Med 2013;368:2236-2237.

- 32 Lee YS, Challis BG, Thompson DA, Yeo GS, Keogh JM, Madonna ME, Wraight V, Sims M, Vatin V, Meyre D, Shield J, Burren C, Ibrahim Z, Cheetham T, Swift P, Blackwood A, Hung CC, Wareham NJ, Froguel P, Millhauser GL, O'Rahilly S, Farooqi IS: A POMC variant implicates beta-melanocyte-stimulating hormone in the control of human energy balance. Cell Metab 2006;3:135-140.
33 Yeo GS, Farooqi IS, Aminian S, Halsall DJ, Stanhope RG, O'Rahilly S: A frameshift mutation in MC4R associated with dominantly inherited human obesity. Nat Genet 1998;20: 111-112.

34 Loos RJ, Lindgren CM, Li S, et al: Common variants near MC4R are associated with fat mass, weight and risk of obesity. Nat Genet 2008;40:768-775.

35 Xi B, Takeuchi F, Chandak GR, Kato N, Pan HW, Zhou DH, Pan HY, Mi J: Common polymorphism near the MC4R gene is associated with type 2 diabetes: data from a meta-analysis of 123,373 individuals. Diabetologia 2012; 55:2660-2666.
Valladares M, Dominguez-Vasquez P, Obregon AM, Weisstaub G, Burrows R, Maiz A, Santos JL: Melanocortin-4 receptor gene variants in Chilean families: association with childhood obesity and eating behavior. Nutr Neurosci 2010;13:71-78.

37 Yeo GS, Heisler LK: Unraveling the brain regulation of appetite: lessons from genetics. Nat Neurosci 2012;15:1343-1349.

38 Cuypers KF, Loos RJ, Kvaloy K, Kulle B, Romundstad P, Holmen TL: Obesity-susceptibility loci and their influence on adiposityrelated traits in transition from adolescence to adulthood - the HUNT study. PLoS One 2013;7:e46912.

39 Loos RJ: Genetic determinants of common obesity and their value in prediction. Best Pract Res Clin Endocrinol Metab 2012;26: 211-226. 